\title{
CONTROLE DA TRANSPARÊNCIA NA CONTRATAÇÃO PÚBLICA NO BRASIL - O ACESSO À INFORMAÇÃO COMO FORMA DE VIABILIZAR O CONTROLE SOCIAL DA ADMINISTRAÇÃO PÚBLICA ${ }^{1}$
}

\section{CONTROL IN HIRING TRANSPARENCY PUBLIC IN BRAZIL - ACCESS TO INFORMATION AS A FORM OF ENABLE SOCIAL CONTROL OF PUBLIC ADMINISTRATION}

Caroline Müller Bitencourt ${ }^{2}$ Janriê Rodrigues Reck ${ }^{2}$

Recebido em: 26/07/ 2016 Aceito em: 21/09/2016

caroline.mb@terra.com.br janrieheck@ibest.com.br corruptivas dentro dos órgãos da Administração Pública, pois além de ser uma forma de inserção do particular nos ditames públicos do Brasil, gera como consequência um efetivo controle social.

Abstract: The article aims to discuss how transparency has avoided corrupting practices within the organs of Public Administration, as well as being a way to insert namely the public dictates of brazil, generates as a consequence an effective social control.

\section{INTRODUÇÃO}

O presente artigo visa discutir a importância da transparência como forma de fomento à participação e, consequentemente, como forma de viabilizar o controle social. Parte-se da problemática se o acesso à informação e a transparência no Brasil têm sido efetivo no sentido de permitir o exercício do controle social?

Para enfrentar tal questão, tem-se como objetivo analisar a evolução do acesso a informação e o dever de transparência estatal após a Constituição de 1988, bem como associar estes mecanismos como instrumentos capazes viabilizar efetiva participação e controle social no Brasil, com ênfase a fiscalização da contratação pública a fim de evitar ou punir práticas corruptivas por parte dos gestores públicos.

Primeiramente, busca-se fazer uma relação do acesso a informação e o dever de transparência como fatores propulsores da participação e controle social no Brasil. A posteriori, constrói-se uma linha evolutiva do acesso a informação e transparência a partir da legislação brasileira e de programas e, por fim, será brevemente discutido um caso polêmico da jurisprudência brasileira que envolveu prática de atos corruptivos na contratação pública e que o dever de transparência e acesso à informação foram de fundamental importância para propiciar não apenas o controle desses atos, mas também para buscar a punição de seus causadores.

\footnotetext{
${ }^{1}$ Este artigo é o resultado de um seminário realizado em Julho de 2015 na Universidade da Coruña Espanha, e contou com financiamento da CAPES/DGPU projeto 332/15 para a publicação de seus resultados.

${ }^{2}$ Universidade de Santa Cruz do Sul - UNISC - Santa Cruz do Sul - Rio Grande do Sul - Brasil.
} 


\section{BREVES APONTAMENTOS SOBRE A LIBERDADE DE INFORMAÇÃO NA CONSTITUIÇÃO DE 1988 E O DEVER DE INFORMAÇÃO POR PARTE DOS ENTES PÚBLICOS}

A Constituição da República de 1988 prevê em seu capítulo sobre os direitos e garantias individuais a liberdade de informação, consoante redação do inciso XIV do artigo 5ํㅡ, reproduzido ipsis litteris: "é assegurado a todos o acesso à informação e resguardado o sigilo da fonte, quando necessário ao exercício profissional". Nesse sentido, restou consolidado o entendimento que o acesso às informações é direito fundamental subjetivo, muito embora, sabe-se que historicamente esse direito fundamental não possa ser lido de forma descontextualizada do contexto histórico que antecedeu a Constituição de 1988, qual seja, o período que envolveu a ditadura militar. Logo, aqui se está tratando da informação relevante sob a ótica do interesse público, haja vista a igualmente importante proteção do direito de intimidade e privacidade.

O direito de ser informado, compreendido como o direito de receber informações, não pode ser entendido sem algumas restrições exegéticas. É que só se pode investir alguém no direito de receber informações quando simultaneamente atribuir-se a outrem o dever de informar. Nessa matéria, a Constituição Federal foi terminante ao atribuir exclusivamente ao Poder Público (art. 5o, XXXIII, e 37, caput) o dever de informar. Assim sendo, pode-se concluir que o direito de ser informado assume dois sentidos. Primeiro, o direito de receber as informações veiculadas sem interferência estatal, numa interface com o direito de informar. Segundo, o direito de ser mantido constantemente informado sobre os negócios e atividades públicas ${ }^{3}$.

Corroborando com tal entendimento, o constituinte ainda dispôs no inciso XXXIII no mesmo art. 5o o dever do Estado em prestar tal informação, gerando um binômio: direito do sujeito $\mathrm{x}$ dever da administração, senão vejamos a redação do referido inciso: "todos têm direito a receber dos órgãos públicos informações de seu interesse particular, ou de interesse coletivo ou geral, que serão prestadas no prazo da lei, sob pena de responsabilidade, ressalvadas aquelas cujo sigilo seja imprescindível à segurança da sociedade e do Estado".

Assim, tratando-se de liberdade de informação, deve-se estar atento ao fato de que a transmissão e o acesso à informação, exata e verificável, é a regra que se impõe, enquanto que o sigilo, a exceção.

Obviamente tal tratamento constitucional, não é prerrogativa exclusiva da Constituição brasileira:

as constituições de um número crescente de países estipulam proteção específica ao direito a informação. A Suécia oferece um exemplo interessante, já que sua Lei de Liberdade de Imprensa, adotada em 1766, tem força constitucional. Esta lei contém disposições abrangentes sobre o direito à informação. Nos últimos dez anos, vários países que, recentemente, adotaram sistemas multipartidários ou que estão em transição para a democracia, incluíram de forma explícita o direito ao direito

\footnotetext{
${ }^{3}$ ARAÚJO, Luiz Alberto David Araújo; NUNES JUNIOR, Vidal Serrano. Curso de Direito Constitucional. 8. ed., rev. e atual. São Paulo: Saraiva, 2004. p. 120.
}

Revista do Direito [ISSN 1982-9957]. Santa Cruz do Sul, v. 2, n. 49, p. 96-115, mai./ago. 2016. https://online.unisc.br/seer/index.php/direito/index 
à informação em suas Constituições. Alguns exemplos de diferentes regiões do mundo incluem a Bulgária (Constituição de 1991,Artigo 41), Estônia (Constituição de 1992, Artigo 44), Hungria (Constituição de 1949, Artigo 61(1), Lituânia(Constituição de 1992, Artigo 25(5)), Malawi (Constituição de 1994, Artigo 37), México (Constituição de 1917, Artigo 6), Filipinas (Constituição de 1987, Artigo III(7), Polônia (Constituição de 1997, Artigo 61), Romênia(Constituição de 1991, Artigo 31), África do Sul (Constituição de 1996, Seção 32) e Tailândia (Constituição de 2007, Seção 56). ${ }^{4}$

Não restam dúvidas que o acesso à informação está conectado com outros direitos fundamentais, como a própria figura da cidadania e do direito à boa administração pública, pois o conhecimento é fundamental para a participação do indivíduo na tomada de decisão dos interesses públicos. Uma administração transparente permite a participação do cidadão na gestão e no controle da administração pública e, para que essa expectativa se torne realidade, é essencial que ele tenha capacidade de conhecer e compreender as informações divulgadas, ou seja, é um direito que não basta para sua realização o cumprimento de seus aspectos formais, é necessária a preocupação acerca da qualidade e acessibilidade da informação prestada. Daí a ideia da informação estar diretamente conectada com a possibilidade de maior participação social.

As políticas que tenham o objetivo de promover acesso à informação pública implicam necessariamente ações que possibilitem acesso a fóruns plurais de discussões, a instituições que prestem contas ao cidadão, a leis de acesso à informação, a proteções contra a negação de prestação de informações por parte de órgãos públicos e à liberdade de imprensa. ${ }^{5}$

A participação social ${ }^{6}$ consiste, portanto, em canais institucionais de participação na gestão governamental, com a presença de novos sujeitos coletivos nos processos decisórios. Nestes termos, apesar de a participação social ser praticamente inseparável do chamado controle social, não se pode dizer que possuem absolutamente o mesmo sentido. Destaca-se que há pontos importantes na distinção dessas modalidades, sendo talvez, o principal ponto o momento da tomada de decisão.

A participação popular ocorre no momento da tomada de decisão pela Administração Pública, que interage com a esfera pública; já o controle social ocorre após esse processo, com intuito de verificar se as decisões tomadas seguiram seu curso e foram concretizadas pela administração pública da forma estabelecida em lei. Assim sendo, todo controle pressupõe a

\footnotetext{
${ }^{4}$ MENDEL, Toby. Liberdade de informação: um estudo de direito comparado. 2. ed. Brasília: UNESCO, 2009, p. 34-35.

${ }^{5}$ LOPES, Cristiano Aguiar. Acesso a informação pública para a melhoria da qualidade dos gastos públicos: literatura, evidências empíricas e o caso brasileiro. Cadernos de Finanças Públicas, Brasília, n. 8, p. 5-40, dez. 2007. Disponível em: www.esaf.fazenda.gov.br/a_esaf/biblioteca/arquivos-gerais/arquivo.2014-0521.1477207388. Acesso em: 10 set. 2015.

${ }^{6}$ Disponível em:<https://online.unisc.br/seer/index.php/direito/article/view/6005/4082>. Acesso em: 20 nov 2015.
}

Revista do Direito [ISSN 1982-9957]. Santa Cruz do Sul, v. 2, n. 49, p. 96-115, mai./ago. 2016. https://online.unisc.br/seer/index.php/direito/index 
participação, mas nem toda participação social é uma forma de controle social. O fato é que para o exercício de ambos, a transparência sobre as ações governamentais é fundamental.

O controle social e a participação popular são irmãos siameses. Entretanto, o controle social é distinto da participação popular. A participação popular ocorre no momento da tomada de decisões, antes ou concomitante à elaboração do ato da Administração, é um poder político de elaboração de normas jurídicas. O controle social pode se concretizar em dois momentos: 1 - análise jurídica da norma estabelecida pela Administração Pública, como a relação de compatibilidade com outras normas de hierarquia superior; 2 - fiscalização da execução ou aplicação destas normas jurídicas ao caso concreto (grifos originais). ${ }^{7}$

Contudo, antes de adentrar propriamente na temática específica cabe referir a importância do papel do controle em se tratando de um Estado Democrático de Direito, pois a atividade de controle, em princípio, é uma atividade neutra, ou seja, não tem um conteúdo a priori, no sentido que é uma função que se justifica na medida em que adéqua e redireciona e se condicionada a partir do contexto em que se insere, e em consonância com as diretrizes estabelecidas por um marco de referência.

Essa questão, observada no histórico do Direito Constitucional brasileiro, provavelmente em decorrências das raízes da própria colonização, o direito administrativo foi concebido como um direito autoritário, situação que aos dias de hoje não pode ser mais afirmada ante a estreita conexão da administração pública com a esfera pública, especialmente no âmbito dos instrumentos de controle amplamente alargados no direito contemporâneo. É certo dizer, para além da preocupação com deveres formais, o direito administrativo contemporâneo volta-se aos deveres substanciais e, não restam dúvidas que a moralidade administrativa assume grande relevo nessas significativas mudanças da forma como compreender o direito administrativo na relação governante, governado, interesse público e controle da administração pública.

Dito isso, dois temas/palavras com significados distintos nos interessam para discutir o controle da ética pública através do princípio da moralidade administrativa: responsabilidade e controle $^{8}$. Responsabilidade, que para Justin Filho "[...] consiste na submissão da organização estatal ao dever jurídico-político de prestar informações e contas por suas ações e omissões e de corrigir imperfeições verificadas por sua conduta", (administração pública) face ao controlante (administrado); enquanto o Controle, como definido por Justin Filho "[...] é um processo de redução de poder, entendida essa expressão no sentido de

\footnotetext{
${ }^{7}$ SIRAQUE, Vanderlei. O controle social da função administrativa do Estado: possibilidades e limites na Constituição de 1988. 2004. 212 f. Dissertação (Mestrado em Direito) - Pontifícia Universidade Católica de São Paulo, 2004, p. 124.

${ }^{8}$ Disponível em:< https://online.unisc.br/seer/index.php/direito/article/view/5650/4086>. Acesso em: 08 jan 2016.

${ }^{9}$ JUSTEN FILHO, Marçal. Curso de Direito Administrativo. São Paulo: Editora Saraiva, 2008. p.947.
} 
imposição da vontade e do interesse de um sujeito sobre outrem"10, ou seja, a situação jurídica do controlante (no caso o administrado) ante ao controlado (administração pública) - o poder que possuem os governados de reduzir o poder da administração pública de decidir.

Não restam dúvidas que justamente por não ser o proprietário do interesse que tutela, a administração pública responde por seus atos perante seus administrados, da mesma forma que é de comum acordo o fato do controle ser ínsito da própria atividade administrativa - aquele que administra, administra em nome de outrem - ou de todos, em decorrência disso, só está autorizado a agir em nome do interesse público.

Existe um momento constitucional no qual a pretensão é controlar as possibilidades de existência normativa de uma determinada comunidade política, tratando-se, assim, do controle da qualidade de razão de ser enquanto discurso constitucional; por outro lado, o controle atua como um momento reformador, ou seja, como técnica da dogmática o controle busca o desempenho da atuação jurídica da ordem social e política preestabelecida na ordem constitucional.

Toda a forma de instituição do próprio controle, ou seja, do preenchimento de seus conteúdos bem como seu campo de incidência e limites de atuação deverá ser democrática, haja vista que a democracia é o único método admitido pela teoria contemporânea como método de gestão do poder, que por sua vez, através da ordem constitucional realiza duas de suas principais funções.

A primeira função, chamada de função de legitimidade, decorre da soberania popular, como o princípio que se responsabiliza pela tomada de decisão no que se trata de interesse público. Destacase que para a concepção habermasiana, soberania popular e direitos fundamentais podem ser tidos como co-originários, ou seja, não existe nenhum conflito ou sobreposição de um em relação a outro, logo, trata-se de controle de formação da vontade política ${ }^{11}$.

A segunda função refere-se à função de controle, em que se procura criar práticas que tentem obstaculizar os desvios desse poder, buscando seu uso adequado. Assim, a função de legitimidade estaria no elemento fundante, enquanto a função de controle estaria no elemento de garantia. A questão relaciona-se ao controle de adequação desse poder, muito embora, essa diferenciação não se dê de forma estanque, antes pelo contrário, pois tanto os elementos de legitimação como de correção encontram-se presente em cada uma das dimensões ${ }^{12}$.

Sendo assim, falar em democracia é falar em controle.

\section{A FALTA DE INFORMAÇÃO COMO UM DOS ENTRAVES AO CONTROLE SOCIAL DA ADMINISTRAÇÃO PÚBLICA E CENÁRIO PARA PROPAGAÇÃO DE PRÁTICAS CORRUPTIVAS}

Toda vez que se propicia um cenário de informação, uma arena pública e se reconhece como integrante da tomada de decisão está se criando um ambiente favorável ao controle social. Sendo assim, todos os orçamentos participativos, as audiências públicas, os conselhos municipais e outros,

\footnotetext{
${ }^{10}$ JUSTEN FILHO, Marçal. Curso de Direito Administrativo. São Paulo: Editora Saraiva, 2008. p.870

${ }^{11}$ PEREIRA, Rodolfo Vianna. Direito Constitucional democrático: controle de participação como elementos fundantes e garantidores de constitucionalidade. 2. ed. Rio de Janeiro: Lúmen Juris, 2010.

12 PEREIRA, Rodolfo Vianna. Direito Constitucional democrático: controle de participação como elementos fundantes e garantidores de constitucionalidade. 2. ed. Rio de Janeiro: Lúmen Juris, 2010
} 
são formas de criar ambientes propícios tanto a participação popular como ao controle social, haja vista serem canais de comunicação com a sociedade e o interesse público e com a tomada de decisões por parte da administração pública.

A finalidade principal da transparência só pode ser alcançada mediante a conversão da informação em instrumento de ação do cidadão, o que nem sempre é algo fácil de alcançar. As duas principais dificuldades estão associadas à baixa escolarização da população brasileira, especialmente a "alfabetização digital", e ao "hermetismo da linguagem técnica" (Culau \& Fortis, 2006), daí a necessidade de utilização de uma "linguagem cidadã", segundo a Cartilha elaborada pela CGU, garantindo a leitura fácil de informações e dados. Nesta "cultura do acesso", a informação compreensível pertence ao cidadão e, a partir delas, as demandas sociais podem e devem ser atendidas. ${ }^{13}$

Fraudes e atos de corrupção encontram oportunidades propícias para propagação em ambientes nos quais a gestão pública pode escamotear informações por julgá-las impróprias para o acesso generalizado. No Brasil, a Lei ํㅜ 12.527, de 18 de novembro de 2011, busca tornar menos obscuro o conhecimento da informação por parte dos cidadãos, no que se refere à forma como os nossos recursos públicos são administrados. Nas lições de Bandeira de Mello:

[...]o dever administrativo de manter plena transparência em seus comportamentos. Não pode haver em um Estado Democrático de Direito, no qual o poder reside no povo (art. 1ํ, parágrafo único, da Constituição), ocultamento aos administrados dos assuntos que a todos interessam, e muito menos em relação aos sujeitos individualmente afetados por alguma medida $^{14}$.

O acompanhamento dos recursos financeiros da gestão pública permite à sociedade civil exercer um papel fundamental na identificação de fraudes; suas ocorrências impedem o crescimento do país, solapando a legitimidade da gestão pública, fato que pode ocasionar uma redução do bem estar coletivo, em prol de interesses individuais, ocasionando a queda de sua imagem.

\footnotetext{
${ }^{13}$ GRUMAN, Marcelo. Lei de Acesso à Informação: notas para reflexão e um breve exemplo. Revista Espaço Acadêmico, n. 141, p. 90-99, fev. 2013. Disponível em:

www.periodicos.uem.br/ojs/index.php/EspacoAcademico/article/viewFile/18873/10406. Acesso em: 10 set. 2015.

${ }^{14}$ MELLO, Celso Antônio Bandeira de. Curso de Direito Administrativo. 27. ed. São Paulo: Malheiros, 2010, p. 114.
}

Revista do Direito [ISSN 1982-9957]. Santa Cruz do Sul, v. 2, n. 49, p. 96-115, mai./ago. 2016. https://online.unisc.br/seer/index.php/direito/index 
Sempre é bom lembrar que a manipulação de dados divulgados por governos com o intuito de fazer com que seus resultados pareçam melhores do que realmente são é algo bastante comum em democracias, mesmos nas mais consolidadas. Metodologia, forma de divulgação, base de comparação, apresentação de informações, enfim, uma série de fatores pode ser utilizada para a maquiagem de dados oficiais. ${ }^{15}$

Por conseguinte, o acesso à informação, mais do que um direito do cidadão, é um dever constitucional imposto à Administração Pública. Nesse sentido, vale recordar dos termos do artigo 37 da Constituição Federal: "A administração pública direta e indireta de qualquer dos Poderes da União, dos Estados, do Distrito Federal e dos Municípios obedecerá aos princípios da legalidade, impessoalidade, moralidade, publicidade e eficiência".

\title{
4. A LINHA EVOLUTIVA EM RELAÇÃO A REGULAMENTAÇÃO DO ACESSO À INFORMAÇÃO NO BRASIL
}

Para compreender como se deu a viabilização do acesso à informação no Brasil, a presente linha evolutiva nos mostra que apesar dos dispositivos serem originários na Constituição de 1988, foi com a evolução legislativa que se construiu a instrumentalização desse acesso, não enquanto acesso à informação passiva, mas via informação ativa ${ }^{16}$ em relação ao dever da administração pública.

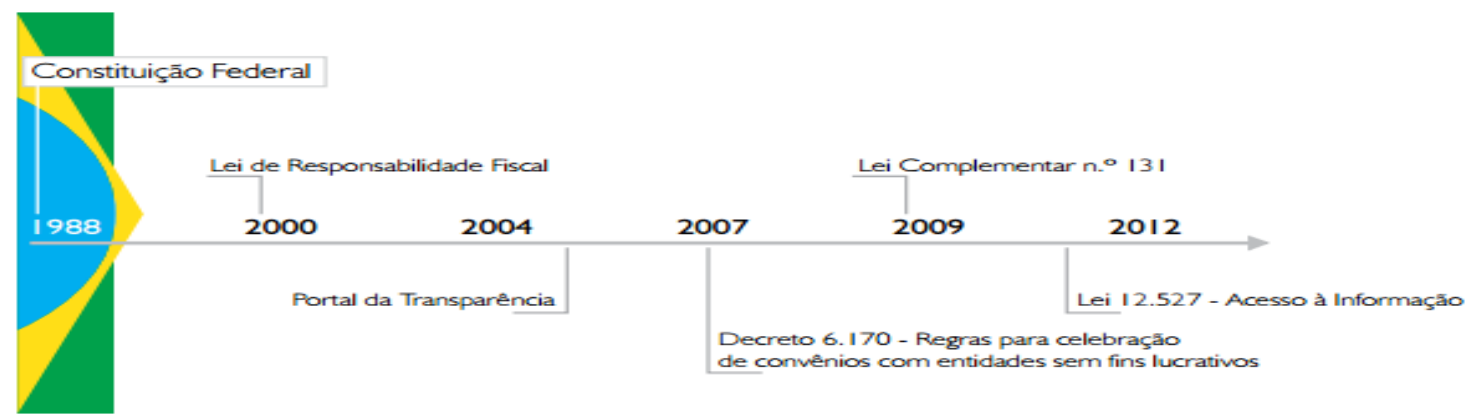

\author{
Ilustração extraída do "Manual da lei de acesso à informação para Estados e \\ Municípios"17.
}

\footnotetext{
${ }^{15}$ LOPES Cristiano Aguiar. Acesso a informação pública para a melhoria da qualidade dos gastos públicos: literatura, evidências empíricas e o caso brasileiro. Cadernos de Finanças Públicas, Brasília, n. 8, p. 5-40, dez. 2007. Disponível em: www.esaf.fazenda.gov.br/a_esaf/biblioteca/arquivos-gerais/arquivo.2014-05-

21.1477207388. Acesso em: 10 set. 2015.

${ }^{16}$ Chamamos de informação passiva, aquela que necessita de provocação por parte do cidadão para que o poder público preste a informação a partir do órgão competente quando acionado, já a informação ativa é aquela em que os órgãos públicos ou entidades governamentais alimentam a sites a fim de viabilizar o acesso sem que haja qualquer tipo de provocação, ou seja, ele é o sujeito ativo desse processo de informação.

${ }^{17}$ Quadro disponível em: www.cgu.gov.br/Publicacoes/transparencia-publica/brasiltransparente/arquivos/manual_lai_estadosmunicipios.pdf. Acesso em: 30 set. 2015.
} 


\subsection{A Lei de Responsabilidade Fiscal no 101/2000 e a Lei Complementar no 131/2009}

A Responsabilidade Fiscal está ancorada em quatro grandes objetivos destinados a função pública: o planejamento, a transparência, o controle e a responsabilidade. O presente trabalho destaca o princípio da transparência, que certamente permitirá o controle democrático. Na Lei de Responsabilidade Fiscal - LRF, visa-se a instrumentalização da transparência através da abertura de canais democráticos institucionalizados, tais como a participação em audiências públicas e a ampla divulgação das informações gerenciais, através do Relatório Resumido da Execução Orçamentária, do Relatório de Gestão Fiscal, bem como dos Anexos de Metas e Riscos Fiscais.

Lembrando que todos os Entes Federativos (União, Estados, Municípios e Distrito Federal) estão compreendidos o Poder Executivo, o Poder Legislativo, neste abrangidos os Tribunais de Contas, o Poder Judiciário e o Ministério Público, estão sujeitos ao cumprimento da lei:

Art. 2ํㅜㄹ Para os efeitos desta Lei Complementar, entende-se como:

I - ente da Federação: a União, cada Estado, o Distrito Federal e cada Município;

II - empresa controlada: sociedade cuja maioria do capital social com direito a voto pertença, direta ou indiretamente, a ente da Federação;

III - empresa estatal dependente: empresa controlada que receba do ente controlador recursos financeiros para pagamento de despesas com pessoal ou de custeio em geral ou de capital, excluídos, no último caso, aqueles provenientes de aumento de participação acionária;

IV - receita corrente líquida: somatório das receitas tributárias, de contribuições, patrimoniais, industriais, agropecuárias, de serviços, transferências correntes e outras receitas também correntes, deduzidos:

a) na União, os valores transferidos aos Estados e Municípios por determinação constitucional ou legal, e as contribuições mencionadas na alínea a do inciso I e no inciso II do art. 195, e no art. 239 da Constituição;

b) nos Estados, as parcelas entregues aos Municípios por determinação constitucional;

c) na União, nos Estados e nos Municípios, a contribuição dos servidores para o custeio do seu sistema de previdência e assistência social e as receitas provenientes da compensação financeira citada no $\S 9^{\circ}$ do art. 201 da Constituição ${ }^{18}$.

\footnotetext{
${ }^{18}$ BRASIL. Lei Complementar no 101, de 4 de maio de 2000. Estabelece normas de finanças públicas voltadas para a responsabilidade na gestão fiscal e dá outras providências. Diário Oficial [da] República Federativa do Brasil, Brasília, DF, 05 mai. 2000. Disponível em: www.planalto.gov.br/ccivil_03/leis/LCP/Lcp101.htm. Acesso em: 30 set. 2015.
}

Revista do Direito [ISSN 1982-9957]. Santa Cruz do Sul, v. 2, n. 49, p. 96-115, mai./ago. 2016. https://online.unisc.br/seer/index.php/direito/index 
Segundo o art. 48 da LRF, a transparência é assegurada através da divulgação ampla, inclusive pela internet, de planos, orçamentos e leis de diretrizes orçamentárias; relatórios de prestações de contas e respectivos pareceres prévios; relatórios resumidos da execução orçamentária e gestão fiscal, bem como das versões simplificadas de tais documentos. Contudo, tal dispositivo sofreu significativas mudanças com a Lei Complementar 131/2009.

A Lei Complementar 131, de 27 de maio de 2009, alterou a redação da Lei de Responsabilidade Fiscal no que se refere à transparência da gestão fiscal, inovando ao determinar a disponibilização, em tempo real, de informações pormenorizadas sobre a execução orçamentária e financeira da União, dos Estados, do Distrito Federal e dos Municípios. ${ }^{19}$ Eis a redação do art. 48 da Lei de Responsabilidade Fiscal após a referida alteração legislativa.

Art. 48. São instrumentos de transparência da gestão fiscal, aos quais será dada ampla divulgação, inclusive em meios eletrônicos de acesso público: os planos, orçamentos e leis de diretrizes orçamentárias; as prestações de contas e o respectivo parecer prévio; o Relatório Resumido da Execução Orçamentária e o Relatório de Gestão Fiscal; e as versões simplificadas desses documentos.

Parágrafo único. A transparência será assegurada também mediante: (Redação dada pela Lei Complementar no 131, de 2009).

I - incentivo à participação popular e realização de audiências públicas, durante os processos de elaboração e discussão dos planos, lei de diretrizes orçamentárias e orçamentos; (Incluído pela Lei Complementar no 131, de 2009).

II - liberação ao pleno conhecimento e acompanhamento da sociedade, em tempo real, de informações pormenorizadas sobre a execução orçamentária e financeira, em meios eletrônicos de acesso público; (Incluído pela Lei Complementar no 131, de 2009).

III - adoção de sistema integrado de administração financeira e controle, que atenda a padrão mínimo de qualidade estabelecido pelo Poder Executivo da União e ao disposto no art. 48-A. (Incluído pela Lei Complementar no 131, de 2009). (Vide Decreto no 7.185, de 2010)

Art. 48-A. Para os fins a que se refere o inciso II do parágrafo único do art. 48, os entes da Federação disponibilizarão a qualquer pessoa física ou jurídica o acesso a informações referentes a: (Incluído pela Lei Complementar № 131, de 2009).

I - quanto à despesa: todos os atos praticados pelas unidades gestoras no decorrer da execução da despesa, no momento de sua realização, com a

\footnotetext{
${ }^{19}$ O chamado "tempo real" encontra-se definido pelo Decreto no 7.185/2010. A liberação em tempo real se refere à disponibilização das informações, em meio eletrônico que possibilite amplo acesso público, até o primeiro dia útil subsequente à data do registro contábil no respectivo sistema, sem prejuízo do desempenho e da preservação das rotinas de segurança operacional necessários ao seu pleno funcionamento.
}

Revista do Direito [ISSN 1982-9957]. Santa Cruz do Sul, v. 2, n. 49, p. 96-115, mai./ago. 2016. https://online.unisc.br/seer/index.php/direito/index 
disponibilização mínima dos dados referentes ao número do correspondente processo, ao bem fornecido ou ao serviço prestado, à pessoa física ou jurídica beneficiária do pagamento e, quando for o caso, ao procedimento licitatório realizado; (Incluído pela Lei Complementar no 131, de 2009). II - quanto à receita: o lançamento e o recebimento de toda a receita das unidades gestoras, inclusive referente a recursos extraordinários. (Incluído pela Lei Complementar ํㅡㄴ 131, de 2009) ${ }^{20}$.

Assim, conforme disposto na LC 131, o ente que não disponibilizar as informações no prazo estabelecido fica impedido de receber transferências voluntárias.

A transparência está associada à divulgação de informações que permitam que sejam averiguadas as ações dos gestores e a consequentemente responsabilização por seus atos. Logo, não há o que se falar em controle, sem o devido cumprimento dos deveres de transparência pública.

\subsection{Portal da Transparência}

Lembrando que na linha do tempo apresentada, constam os chamados portais da transparência ${ }^{21}$, que desde o ano de 2004, apresenta ao cidadão informações sobre a aplicação de recursos públicos federais, a partir da consolidação de milhões de dados oriundos de diversos órgãos do Governo Federal relativos a Programas e Ações de Governo. O Portal da Transparência é

\footnotetext{
${ }^{20}$ BRASIL. Lei Complementar no 101, de 4 de maio de 2000. Estabelece normas de finanças públicas voltadas para a responsabilidade na gestão fiscal e dá outras providências. Diário Oficial [da] República Federativa do Brasil, Brasília, DF, 05 mai. 2000. Disponível em: www.planalto.gov.br/ccivil_03/leis/LCP/Lcp101.htm. Acesso em: 30 set. 2015.

${ }^{21}$ Já as Páginas da Transparência Pública são disponibilizadas mediante adesão do órgão/entidade. As Páginas de Transparência são carregadas pelo Serviço Federal de Processamento de Dados (SERPRO), o qual mantêm rotinas automáticas de obtenção de dados de licitação e contratos do órgão/entidade a partir do Sistema Integrado de Administração de Serviços Gerais (SIASG), de dados de diárias e passagens do Sistema de Concessão de Diárias e Passagens (SCDP) e de dados de execução orçamentária e financeira do Sistema Integrado de Administração Financeira (SIAFI). As Páginas de Transparência Pública apresentam os dados referentes às despesas realizadas por cada órgão e entidade da Administração Pública Federal com informações sobre execução orçamentária, licitações, contratações, convênios, diárias e passagens. As páginas de Transparência Pública dão continuidade às ações de governo voltadas para o incremento da transparência da gestão e do controle social e, ainda, complementam as informações disponíveis no Portal da Transparência. Por meio do Decreto Presidencial no 5.482, de 30.05.2005, o Governo Federal determinou a divulgação, na Internet, de informações relativas à execução orçamentária e financeira dos órgãos e entidades da Administração Pública Federal, direta e indireta. A Portaria Interministerial no 140, de 16 de março de 2006, que disciplina a matéria, estabelece que os citados órgãos e entidades deverão manter em seus respectivos sítios eletrônicos na Internet página denominada "Transparência Pública", tendo por conteúdo mínimo informações sobre a execução orçamentária e financeira, licitações, contratos, convênios e despesas com passagens e diárias que ocorrerem em seus respectivos âmbitos. Por sua vez, a Página de Acesso à Informação do órgão/entidade, exigida pela Lei de Acesso a Informação - LAI (Lei no 12.527, de 18/11/2011) é de responsabilidade do próprio órgão/entidade, sendo que há indicação de link para o Portal da Transparência e para a Página da Transparência do órgão/entidade, no caso de despesas, licitações e contratos. Além disso, na Página de Acesso à Informação o órgão/entidade pode, a seu critério, inserir outras informações que julgar pertinentes. PORTAL DA TRANSPARÊNCIA. Disponível em: www.portaldatransparencia.gov.br/faleConosco/perguntas-tema-sobre-o-portal.asp\#8. Acesso em 06 de julho de 2015.
}

Revista do Direito [ISSN 1982-9957]. Santa Cruz do Sul, v. 2, n. 49, p. 96-115, mai./ago. 2016. https://online.unisc.br/seer/index.php/direito/index 
gerenciado e mantido pela Controladoria-Geral da União, conforme ele mesmo anuncia, consolida dados extraídos de Sistemas Estruturadores, como da execução financeira do SIAFI, de convênios do SIAFI e do Sistema de Convênios (SICONV), e de servidores do Sistema Integrado de Administração de Recursos Humanos (SIAPE), além disso, do cadastro de beneficiários de Programas Sociais e de Cartão de Pagamentos do Governo Federal e da Defesa Civil, dentre outros. E são oriundos da Secretaria do Tesouro Nacional, do Ministério do Planejamento, da Caixa Econômica Federal, do Banco do Brasil S.A, e demais órgãos do governo federal ${ }^{22}$.

No Brasil, verifica-se a existência de portais autônomos e independentes como o portal Transparência Brasil (www.transparencia.org.br) constituídos por grupos não governamentais focados no combate à corrupção. Nestes sites são abordados estudos a respeito de desvios e do mau uso dos recursos públicos, servindo para difundir o conhecimento sobre o tema.

Da mesma forma, o Programa "Olho Vivo no Dinheiro Público", criado pela ControladoriaGeral da União (CGU), possui programação voltada para incentivar o cidadão para o controle social e com educação presencial, educação à distância, distribuição de material didático e incentivo à formação de acervos técnicos em conjunto com o Programa de Fortalecimento da Gestão Pública.

Indubitavelmente, esses sites governamentais e não governamentais são ferramentas importantes na promoção da transparência nacional, diminuindo as barreiras existentes entre a informação e o cidadão.

\subsection{A importância da Lei 12.527/2011 para consolidação da transparência na gestão pública}

A fim de dar seguimento ao estudo, passa-se a discussão da nova regulamentação do acesso à informação e transparência pública, a partir da Lei no 12.527/2011.

$\mathrm{Na}$ definição de transparência no que toca a referida Lei são identificadas características em relação à informação completa, objetiva, confiável e de qualidade, ao acesso, à compreensão e aos canais totalmente abertos de comunicação. Engloba os seguintes atributos: acesso, abrangência, relevância, qualidade e confiabilidade.

Destacam-se alguns aspectos gerais da Lei oㅜ 12.527, de 18 de novembro de 2011, a qual busca regulamentar o direito de acesso à informação previsto na Constituição Federal de 1988

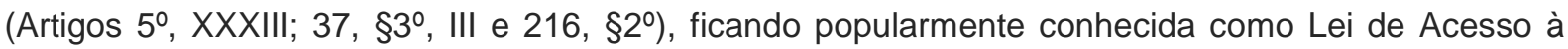
Informação (LAI).

Esta Lei já sofreu regulamentação legislativa pelo Decreto ํo 7.724 de 16 de maio de 2012, podendo-se dizer que o grande avanço foi justamente criar mecanismos que possibilitam que qualquer pessoa, sem necessidade de apresentar motivo, receba informações públicas requeridas a órgãos e entidades a fim de fiscalizar o gerenciamento da coisa pública. Atendendo às exigências constitucionais, pode-se dizer que a publicidade e a transparência das informações são os princípios regentes, enquanto que o sigilo acesso pode ser restringido apenas em situações específicas, muito

\footnotetext{
${ }^{22}$ PORTAL DA TRANSPARÊNCIA. Disponível em: www.portaldatransparencia.gov.br/faleConosco/perguntastema-sobre-o-portal.asp\#8. Acesso em 06 de julho de 2015.
}

Revista do Direito [ISSN 1982-9957]. Santa Cruz do Sul, v. 2, n. 49, p. 96-115, mai./ago. 2016. https://online.unisc.br/seer/index.php/direito/index 
embora depois será discutido a ampla discricionariedade no momento de agravar documentos como sigilosos.

Estão subordinados ao regime da Lei os seguintes órgãos ou entidades:

Art. 10 Esta Lei dispõe sobre os procedimentos a serem observados pela União, Estados, Distrito Federal e Municípios, com o fim de garantir o acesso a informações previsto no inciso XXXIII do art. 5o, no inciso II do $\S$ $3^{\circ}$ do art. 37 e no $\S 2^{\circ}$ do art. 216 da Constituição Federal.

Parágrafo único. Subordinam-se ao regime desta Lei:

I - os órgãos públicos integrantes da administração direta dos Poderes Executivo, Legislativo, incluindo as Cortes de Contas, e Judiciário e do Ministério Público;

II - as autarquias, as fundações públicas, as empresas públicas, as sociedades de economia mista e demais entidades controladas direta ou indiretamente pela União, Estados, Distrito Federal e Municípios.

Art. 20 Aplicam-se as disposições desta Lei, no que couber, às entidades privadas sem fins lucrativos que recebam, para realização de ações de interesse público, recursos públicos diretamente do orçamento ou mediante subvenções sociais, contrato de gestão, termo de parceria, convênios, acordo, ajustes ou outros instrumentos congêneres.

Parágrafo único. A publicidade a que estão submetidas as entidades citadas no caput refere-se à parcela dos recursos públicos recebidos e à sua destinação, sem prejuízo das prestações de contas a que estejam legalmente obrigadas ${ }^{23}$.

Note-se que o artigo $2^{\circ}$ da referida Lei não inova por completo no direito brasileiro, haja vista que ao dispor sobre as normas relativas às transferências de recursos da União mediante convênios e contratos de repasse, já trazia deveres de transparência no gerenciamento dos recursos públicos, a exemplo do art. 13: "a celebração, a liberação de recursos, o acompanhamento da execução e a prestação de contas de convênios, contratos de repasse e termos de parceria serão registrados no SICONV, que será aberto ao público, via rede mundial de computadores - Internet, por meio de página específica denominada Portal dos Convênios. (Redação dada pelo Decreto № 6.619, de 2008)".

São diretrizes básicas da LAI expressas em seu art 3o: I - observância da publicidade como preceito geral e do sigilo como exceção; II - divulgação de informações de interesse público, independentemente de solicitações; III - utilização de meios de comunicação viabilizados pela

23 BRASIL. Lei no 12.527, de 18 de novembro de 2011. Diário Oficial [da] República Federativa do Brasil, Brasília, DF, 18 nov. 2011. Disponível em: www.planalto.gov.br/ccivil_03/_ato2011-2014/2011/lei/l12527.htm. Acesso em: 30 set. 2015.

Revista do Direito [ISSN 1982-9957]. Santa Cruz do Sul, v. 2, n. 49, p. 96-115, mai./ago. 2016. https://online.unisc.br/seer/index.php/direito/index 
tecnologia da informação; IV - fomento ao desenvolvimento da cultura de transparência na administração pública; $\mathrm{V}$ - desenvolvimento do controle social da administração pública.

Destaca-se que na própria explanação das diretrizes fica evidente que a cultura da transparência na gestão pública tem como intuito o fomento do controle social, ou seja, é poder/dever do gestor público criar o ambiente propício para a efetiva existência da participação e controle, atendendo os deveres de uma boa administração pública.

Por conseguinte, para atender à demanda a lei determina que os órgãos públicos criem centros de atendimento dentro de cada órgão chamados SICs (Serviços de Informação ao Cidadão), que ficará a cargo de cada ente federativo à sua alimentação. Nestes termos, resta evidente que tal lei cria o dever da Administração, de ofício, de promover as divulgações mínimas para a sociedade transparência ativa. Na divulgação das informações pelos SICs, deverão constar, no mínimo, segundo art. 8ㅇ § 10: I - Registro das competências e estrutura organizacional, endereços, telefones das unidades, horários de atendimento ao público; II - Registro de quaisquer repasses ou transferências de recursos financeiros; III - Registros das despesas; IV - Informações sobre licitações, seus editais e resultados; contratos celebrados; $V$ - Dados gerais para acompanhamento das ações dos órgãos e entidades; VI - Respostas a perguntas mais frequentes da sociedade.

Ainda conforme art. 8ํ, $\S 40$ os Municípios com população de até 10.000 (dez mil) habitantes ficam dispensados da divulgação obrigatória na internet a que se refere o $\S 20$, mantida a obrigatoriedade de divulgação, em tempo real, de informações relativas à execução orçamentária e financeira, nos critérios e prazos previstos no art. 73-B da Lei Complementar no 101, de 4 de maio de 2000. A grande questão aqui vislumbrada, é que o percentual de municípios com menos de 10.000 (dez mil) habitantes, segundo os últimos dados disponibilizados pelo IBGE (2013), coletados em junho de 2015 , é de que $43,10 \%$ (por cento) dos municípios brasileiros estão dentro do percentual dispensado pela lei. Diga-se também, que são justamente esses municípios que é mais dificultosa a fiscalização, haja vista que muitos sequer têm promotorias instaladas nos seus municípios, atuando em substituições. A notícia positiva, é que muito embora este número significativo de municípios estejam dispensados de cumprir às exigências da lei, muitos têm aderido por conta própria.

Em pesquisa realizada sobre a transparência e o acesso à informação, a Controladoria Geral da União avaliou o grau de cumprimento das normas da LAI por entes da federação. A divulgação dos dados do ranking ocorreu em 15/05/2015, quando foram analisados 492 municípios com até 50 mil habitantes e todas as capitais dos estados e do DF. Na avaliação, todos os entes receberam uma nota de 0 a 10 pontos, calculada pela soma de dois critérios: 1) regulamentação da Lei de Acesso (25\%)e 2) efetiva existência e atuação do Serviço de Informação ao Cidadão (75\%). Como resultado, os Estados mais transparentes da República foram São Paulo e Ceará, enquanto que os menos transparentes foram Amapá e Rio Grande do Norte. Em termos locais, os municípios mais transparentes foram Apiúna (SC); São Paulo (SP); Curitiba (PR) e Brasília (DF), enquanto que os municípios menos transparentes foram Porto Velho (RO) e São Luiz (MA). ${ }^{24}$

\footnotetext{
${ }^{24}$ CONTROLADORIA-GERAL DA UNIÃO. Relatório. Disponível em: relatorios.cgu.gov.br/Visualizador.aspx?id_relatorio=2. Acesso em: 11 mai. 2015.
} 
Conforme mencionado, ainda que a regra seja a informação, o sigilo ainda é permitido em algumas situações, excepcionais, consideradas imprescindíveis à segurança da sociedade ou do Estado, as quais se destacam quando as informações têm o condão de I - Pôr em risco a defesa e a soberania nacionais ou a integridade do território nacional; II - Prejudicar ou pôr em risco a condução de negociações ou as relações internacionais do País, ou as que tenham sido fornecidas em caráter sigiloso por outros Estados e organismos internacionais; III - Pôr em risco a vida, a segurança ou a saúde da população; IV - Oferecer elevado risco à estabilidade financeira, econômica ou monetária do País; V - Prejudicar ou causar risco a planos ou operações estratégicos das Forças Armadas; VI Prejudicar ou causar risco a projetos de pesquisa e desenvolvimento científico ou tecnológico, assim como a sistemas, bens, instalações ou áreas de interesse estratégico nacional; VII - Pôr em risco a segurança de instituições ou de altas autoridades nacionais ou estrangeiras e seus familiares; VIII Comprometer atividades de inteligência, bem como de investigação ou fiscalização em andamento, relacionadas com a prevenção ou repressão de infrações.

Ainda, conforme dicção do artigo $24, \$^{\circ}{ }^{\circ}$ da LAl, é de 25 anos o prazo para disponibilização de informações consideradas ultrassecretas, 15 anos para as consideradas secretas e 5 anos para as informações classificadas como reservadas. Destaca-se, contudo, que os prazos mencionados na lei podem ser alterados a critério da Comissão Mista de Reavaliação de Informação, sempre que verificada que a divulgação pode ocasionar ameaça externa à soberania nacional, integridade do território ou grave risco às relações internacionais do País. Assim, a prorrogação do sigilo poderá se dar uma única vez, por período determinado não superior a 25 anos (para as ultrassecretas), limitando o sigilo ao máximo de 50 anos.

No que se refere a competência para a classificação na administração pública federal, podese identificar a partir do dispositivo da Lei 12.527/11:

Art. 27. A classificação do sigilo de informações no âmbito da administração pública federal é de competência:

I - no grau de ultrassecreto, das seguintes autoridades:

a) Presidente da República;

b) Vice-Presidente da República;

c) Ministros de Estado e autoridades com as mesmas prerrogativas;

d) Comandantes da Marinha, do Exército e da Aeronáutica; e

e) Chefes de Missões Diplomáticas e Consulares permanentes no exterior;

II - no grau de secreto, das autoridades referidas no inciso I, dos titulares de autarquias, fundações ou empresas públicas e sociedades de economia mista;

III - no grau de reservado, das autoridades referidas nos incisos I e II e das que exerçam funções de direção, comando ou chefia, nível DAS 101.5, ou superior, do Grupo-Direção e Assessoramento Superiores, ou de hierarquia equivalente, de acordo com regulamentação específica de cada órgão ou entidade, observado o disposto nesta Lei. 
Chama atenção a possibilidade disposta no grau reservado que se refere as autoridades com função de direção, comando ou chefia ou de hierarquia equivalente da chamada administração pública indireta, haja vista também comportarem interesses privados e a lógica do mercado, jamais podendo tal interesse e sigilo, ao nosso entender, preponderar sobre o dever de transparência do controle da gestão dos recursos públicos, sobrepondo-se aos interesses públicos.

\section{O CASO BNDS E O ACESSO À INFORMAÇÃO: O DEVER DE PREVALÊNCIA DA TRANSPARÊNCIA NA CONTRATAÇÃO PÚBLICA CONTRA ATOS CORRUPTIVOS}

O mandado de segurança $n^{0} 33.340$ teve ensejo com pedido de proteção ao sigilo das negociações que envolveram com a JBS/Friboi e o banco BNDS, a partir da determinação de informações por parte do Tribunal de Contas da União ${ }^{25}$, haja vista o BNDS ser pessoa de direito privado da administração indireta e, portanto, sujeito ao controle fiscal e orçamentário do Tribunal de Contas. O referido mandado foi apreciado pela primeira Turma do Supremo Tribunal Federal, tendo como relator o Ministro Luiz Fux, sendo rejeitado pela maioria dos votos, vencido em parte o Ministro Luís Roberto Barroso. Importa um breve resumo dos trechos extraídos, que destacam o que foi determinante para denegação da ordem:

O TCU determinou o fornecimento de dados pela JBS/Friboi, pessoa que celebrou contratos vultosos com o BNDES, a fim de aferir, por exemplo, os critérios utilizados para a escolha da referida sociedade empresária, quais seriam as vantagens sociais advindas das operações analisadas, se houve cumprimento das cláusulas contratuais, se as operações de troca de debêntures por posição acionária na empresa ora indicada originou prejuízo para o BNDES. II) O TCU não agiu de forma imotivada e arbitrária, e nem mesmo criou exigência irrestrita e genérica de informações sigilosas. Sobre o tema, o ato coator aponta a existência de uma operação da Polícia Federal denominada Operação Santa Tereza que apontou a existência de quadrilha intermediando empréstimos junto ao BNDES, inclusive envolvendo o financiamento obtido pelo Frigorífico Friboi. Ademais, a necessidade do controle financeiro mais detido resultou, segundo o decisum atacado, de um "protesto da Associação Brasileira da Indústria Frigorífica (Abrafigo) contra a política do BNDES que estava levanto à concentração econômica do setor". III) A requisição feita pelo TCU na hipótese destes

\footnotetext{
25 “[...] nuclearmente feito nas pranchetas da Constituição. Foi o legislador de primeiríssimo escalão quem estruturou e funcionalizou todos eles (os Tribunais de Contas), prescindindo das achegas da lei menor. (...) Tão elevado prestígio conferido ao controle externo e a quem dele mais se ocupa, funcionalmente, é reflexo direto do princípio republicano. Pois, numa República, impõe-se responsabilidade jurídica pessoal a todo aquele que tenha por competência (e consequente dever) cuidar de tudo que é de todos". BRITTO, Carlos Ayres. O regime constitucional dos Tribunais de Contas. In: Revista do Tribunal de Contas do Estado do Rio de Janeiro. Volume 8. 2o semestre de 2014. Rio de Janeiro: TCERJ, p. 18 e 20.
} 
autos revela plena3 Supremo Tribunal Federal Documento assinado O documento pode ser acessado no endereço eletrônico O princípio da conformidade funcional a que se refere Canotilho, também, reforça a conclusão de que os órgãos criados pela Constituição da República, tal como o TCU, devem se manter no quadro normativo de suas competências, sem que tenham autonomia para abrir mão daquilo que o constituinte lhe entregou em termos de competências. (CANOTILHO, José Joaquim Gomes. Direito Constitucional e Teoria da Constituição. $5^{\text {a }}$ edição. Coimbra: Almedina, 2002, p. 541.) 11. A Proteção Deficiente de vedação implícita permite assentar que se a publicidade não pode ir tão longe, de forma a esvaziar, desproporcionalmente, o direito fundamental à privacidade e ao sigilo bancário e empresarial; não menos verdadeiro é que a insuficiente limitação ao direito à privacidade revelar-se-ia, por outro ângulo, desproporcional, porquanto lesiva aos interesses da sociedade de exigir do Estado brasileiro uma atuação transparente ${ }^{26}$. (Grifos próprios).

E segue sua argumentação:

12. No caso sub examine: I) O TCU determinou o fornecimento de dados pela JBS/Friboi, pessoa que celebrou contratos vultosos com 0 BNDES, a fim de aferir, por exemplo, os critérios utilizados para a escolha da referida sociedade empresária, quais seriam as vantagens sociais advindas das operações analisadas, se houve cumprimento das cláusulas contratuais, se as operações de troca de debêntures por posição acionária na empresa ora indicada originou prejuízo para o BNDES. II) O TCU não agiu de forma imotivada e arbitrária, e nem mesmo criou exigência irrestrita e genérica de informações sigilosas. Sobre o tema, o ato coator aponta a existência de uma operação da Polícia Federal denominada Operação Santa Tereza que apontou a existência de quadrilha intermediando empréstimos junto ao BNDES, inclusive envolvendo o financiamento obtido pelo Frigorífico Friboi. Ademais, a necessidade do controle financeiro mais detido resultou, segundo o decisum atacado, de um "protesto da Associação Brasileira da Indústria Frigorífica (Abrafigo) contra a política do BNDES que estava levanto à concentração econômica do setor". III) A requisição feita pelo TCU na hipótese destes autos revela plena3 Supremo Tribunal Federal

\footnotetext{
${ }^{26}$ O documento pode ser acessado no endereço eletrônico www.stf.jus.br/portal/autenticacao/ sob o número 8833732. Inteiro Teor do Acórdão - Página 3 de 49 Ementa e Acórdão MS 33340 / DF.
} 
Documento assinado digitalmente conforme MP $n^{\circ} 2.200-2 / 2001$ de 24/08/2001, que institui a Infraestrutura de Chaves Públicas Brasileira - ICPBrasil $^{27}$.

Os principais pontos apontados pelo Supremo ${ }^{28}$ foram os seguintes: I - O controle financeiro das verbas públicas é essencial e privativo do Parlamento como consectário do Estado de Direito; II O primado do ordenamento constitucional democrático assentado no Estado de Direito pressupõe uma transparente responsabilidade do Estado e, em especial, do Governo; III - O sigilo de informações necessárias para a preservação da intimidade é relativizado quando se está diante do interesse da sociedade da sociedade em se conhecer os destinos das verbas públicas. IV Operações financeiras que envolvam recursos públicos não estão abrangidas pelo sigilo bancário a que alude a Lei Complementar oㅜ 105/2001, visto que as operações dessa espécie estão submetidas aos princípios da administração pública insculpidos no art. 37 da Constituição Federal. Em tais situações, é prerrogativa constitucional do Tribunal [TCU] o acesso a informações relacionadas a operações financeiras com recursos públicos; V - O segredo como "alma do negócio" consubstancia a máxima cotidiana inaplicável em casos análogos ao sub judice, tanto mais que, quem contrata com o poder público não pode ter segredos, especialmente se a revelação for necessária para o controle da legitimidade do emprego dos recursos públicos. É que a contratação pública não pode ser feita em esconderijos envernizados por um arcabouço jurídico capaz de impedir o controle social quanto ao emprego das verbas públicas.

O resultado da decisão restou publicada no informativo 787 do STF, com a seguinte redação:

A Turma destacou que, no âmbito do Direito Público, a Administração, também, estaria pautada por princípios basilares estampados no art. 37 da CF, dentre eles o da publicidade, preceito que recomendaria a atuação transparente do agente público. Por se tratar de princípio, ele, também, comportaria exceções, todas fundadas no texto constitucional: a) o sigilo que fosse imprescindível à segurança da sociedade e do Estado (CF, art. $5^{\circ}, \mathrm{XXXIII)}$, e b) o sigilo que dissesse respeito à intimidade ou ao interesse social (CF, art. 5ㅇ, LX). Nesse contexto, seria tarefa simples aceitar que a necessidade de preservação do sigilo bancário e empresarial poderia estar contida nas exceções constitucionais, seja porque resultante da reserva de segurança da sociedade, ou por representar um desdobramento da preservação da intimidade ou do interesse social. Em decorrência dessa premissa, o que se vedaria ao TCU seria a quebra do sigilo bancário e fiscal, "tout court", consoante decisões proferidas no MS 22.801/DF (DJe de 14.3.2008) e no MS 22.934/DF (DJe 9.5.2012) no sentido de que a LC

\footnotetext{
${ }^{27} \mathrm{O}$ documento pode ser acessado no endereço eletrônico www.stf.jus.br/portal/autenticacao/ sob o número 8833732. Inteiro Teor do Acórdão - Página 3 de 49 Ementa e Acórdão MS 33340 / DF.

${ }^{28}$ Sobre a questão da decisão judicial ver <>
} 
105/2001, que dispõe sobre o sigilo das operações de instituições financeiras, não poderia ser manejada pelo TCU para que fosse determinada a quebra de sigilo bancário e empresarial. O caso em comento, entretanto, seria diferente dos referidos precedentes, porquanto a atuação do TCU teria amparo no art. 71 da CF e se destinaria, precipuamente, a controlar as operações financeiras realizadas pelo BNDES e pelo BNDESPAR. Cuidar-se-ia de regular hipótese de controle legislativo financeiro de entidades federais por iniciativa do Parlamento, que o fizera por meio da Comissão de Fiscalização e Controle da Câmara dos Deputados. Nesse particular, o referido órgão determinara ao TCU que realizasse auditoria nas operações de crédito envolvendo as citadas instituições financeiras, com fundamento no art. 71, IV, da CF. Ademais, não se estaria diante de requisição para a obtenção de informações de terceiros, mas de informações das próprias instituições, que contrataram terceiros com o emprego de recursos de origem pública. A pretensão do TCU seria o mero repasse de informações no seio de um mesmo ente da federação, e isso não ostentaria a conotação de quebra de sigilo bancário. Essa diferença seria relevante para legitimar a atuação da Corte de Contas, sob pena de inviabilizar o pleno desempenho de sua missão constitucionalmente estabelecida. $O$ BNDES atuaria como banco de fomento com características muito próprias, sendo um banco de fomento econômico e social, e não uma instituição financeira privada comum. Por mais que ele detivesse a natureza de pessoa de direito privado da Administração Indireta, também sofreria intensa influência do regime de Direito Público. Nessa senda, ressoaria imperioso destacar que o sigilo de informações necessárias para a preservação da intimidade seria relativizado quando se estivesse diante do interesse da sociedade de se conhecer o destino dos recursos públicos. MS 33340/DF, rel. Min. Luiz Fux, 26.5.2015. (MS-33340) $)^{29}$. (Grifos próprios).

Tal decisão foi de extrema importância no cenário brasileiro, no sentido de reforçar a imprescindibilidade do dever de transparência e acesso a informação no que se refere à contratação pública, devendo prevalecer o dever de boa administração pública de prestar contas aos seus administrados da manutenção dos recursos públicos. Reforçando o fato de que a Administração Pública direta ou indireta em um Estado Democrático de Direito deve estar sujeito à fiscalização dos órgãos institucionalizados e acessível ao controle social.

\footnotetext{
${ }^{29}$ STF, informativo no 787. Disponível em: www.stf.jus.br/portal/jurisprudencia/listarJurisprudencia.asp?s1=\%2833340\%2EPROC\%2E\%29\&base=baselnfo rmativo\&url=http://tinyurl.com/nzucr79. Acesso em 06 de junho de 2015.
} 


\section{CONSIDERAÇÕES FINAIS}

Neste breve ensaio construiu-se uma linha evolutiva de como a administração pública brasileira tem se adequado legislativamente e instrumentalmente ao dever de prestar informação e transparência da gestão pública.

Observou-se que a transparência pública é um meio de propiciar acesso a participação e, consequentemente, viabilizar o controle da contratação pública no Brasil. Estabeleceu-se uma relação entre a falta de informação e transparência como sendo uma forma de facilitar a propagação da corrupção administrativa.

Discutiu-se que além de prestar a informação, as legislações têm cobrado qualidade da informação prestada, a fim de viabilizar a interlocução entre administração pública e os administrados.

Após uma breve análise da legislação brasileira, propôs-se a análise de um exemplo prático no direito brasileiro, que ficou conhecido como "caso BNDS", onde empiricamente pode-se comprovar o tratamento que a transparência pública tem recebido da Corte Constitucional brasileira, ao confirmar quem contrata com o poder público não pode ter segredos, especialmente se a revelação for necessária para o controle da legitimidade do emprego dos recursos públicos. É que a contratação pública não pode ser feita em esconderijos envernizados por um arcabouço jurídico capaz de impedir o controle social quanto ao emprego das verbas públicas.

\section{REFERÊNCIAS}

ARAÚJO, Luiz Alberto David Araújo; NUNES JUNIOR, Vidal Serrano. Curso de Direito Constitucional. 8. ed., rev. e atual. São Paulo: Saraiva, 2004.

BARACHO, H.; JATOBÁ, A. C. M. O. Função social e responsabilidade social à luz da Constituição Federal de 1988. Revista do Direito, Santa Cruz do Sul, v. 1, n. 45, jan. - abri., 2015. Disponível em: $<$ https://online.unisc.br/seer/index.php/direito/article/view/6005/4082>. Acesso em: 10 abri. 2016.

BRASIL, STF. Informativo $n^{\circ}$ 787. Disponível em: www.stf.jus.br/portal/jurisprudencia/listarJurisprudencia.asp?s1=\%2833340\%2EPROC\%2E\%29\&base =baselnformativo\&url=http://tinyurl.com/nzucr79. Acesso em 06 de junho de 2015.

Constituição (1988). Constituição da República Federativa do Brasil. Brasília, DF: Senado Federal, 1988.

Decreto ํㅜ 7.185, de 27 de maio de 2010. Diário Oficial [da] República Federativa do Brasil, Brasília, DF, 27 mai. 2010. Disponível em: www.planalto.gov.br/ccivil_03/_ato20072010/2010/decreto/d7185.htm. Acesso em: 30 set. 2015.

. Lei no 12.527, de 18 de novembro de 2011. Diário Oficial [da] República Federativa do Brasil, Brasília, DF, 18 nov. 2011. Disponível em: www.planalto.gov.br/ccivil_03/_ato20112014/2011/lei/l12527.htm. Acesso em: 30 set. 2015.

. Lei Complementar no 101, de 4 de maio de 2000. Estabelece normas de finanças públicas voltadas para a responsabilidade na gestão fiscal e dá outras providências. Diário Oficial [da] República Federativa do Brasil, Brasília, DF, 05 mai. 2000. Disponível em: www.planalto.gov.br/ccivil_03/leis/LCP/Lcp101.htm. Acesso em: 30 set. 2015. 
. Lei Complementar no 131, de 27 de maio de 2009.Diário Oficial [da] República Federativa do Brasil, Brasília, DF, 28 mai. 2009. Disponível em: www.planalto.gov.br/ccivil_03/leis/LCP/Lcp131.htm. Acesso em: 30 set. 2015.

BRITTO, Carlos Ayres. O regime constitucional dos Tribunais de Contas. In: Revista do Tribunal de Contas do Estado do Rio de Janeiro. V. 8. 2ํsemestre de 2014. Rio de Janeiro: TCERJ, p. 18 e 20. Disponível em: www.stf.jus.br/portal/autenticacao.

BUTELER, A. La eficacia de los organismos de control de etica pública y anticorrupción. Revista do Direito, Santa Cruz do Sul, v. 1, n. 45, 2015. Disponível em: < https://online.unisc.br/seer/index.php/direito/article/view/5650/4086>. Acesso em: 10 abri. 2016.

CONTROLADORIA GERAL DA UNIÃO. Relatório. Disponível em:

relatorios.cgu.gov.br/Visualizador.aspx?id_relatorio=2. Acesso em: 11 mai. 2015.

. Manual da Lei de Acesso à Informação para Estados e Municípios. Disponível em: www.cgu.gov.br/Publicacoes/transparencia-publica/brasiltransparente/arquivos/manual_lai_estadosmunicipios.pdf. Acesso em: 30 set. 2015.

Olho vivo no dinheiro público. Disponível em: www.cgu.gov.br/assuntos/controle-social/olhovivo. Acesso em: 30 set. 2015.

GRUMAN, Marcelo. Lei de Acesso à Informação: notas para reflexão e um breve exemplo. Revista Espaço Acadêmico, n. 141, p. 90-99, fev. 2013. Disponível em: www.periodicos.uem.br/ojs/index.php/EspacoAcademico/article/viewFile/18873/10406. Acesso em: 10 set. 2015.

JUSTEN FILHO, Marçal. Curso de Direito Administrativo. São Paulo: Editora Saraiva, 2008.

LOPES Cristiano Aguiar. Acesso a informação pública para a melhoria da qualidade dos gastos públicos: literatura, evidências empíricas e o caso brasileiro. Cadernos de Finanças Públicas, Brasília, n. 8, p. 5-40, dez. 2007. Disponível em: www.esaf.fazenda.gov.br/a_esaf/biblioteca/arquivosgerais/arquivo.2014-05-21.1477207388. Acesso em: 10 set. 2015.

MELLO, Celso Antônio Bandeira de. Curso de Direito Administrativo. 27. ed. São Paulo: Malheiros, 2010.

MENDEL, Toby. Liberdade de informação: um estudo de direito comparado. 2. ed. Brasília: UNESCO, 2009.

PEREIRA, Rodolfo Vianna. Direito Constitucional democrático: controle de participação como elementos fundantes e garantidores de constitucionalidade. 2. ed. Rio de Janeiro: Lúmen Juris, 2010.

PORTAL DA TRANSPARÊNCIA. Disponível em:

www.portaldatransparencia.gov.br/faleConosco/perguntas-tema-sobre-o-portal.asp\#8. Acesso em 06 de julho de 2015.

SIRAQUE, Vanderlei. O controle social da função administrativa do Estado: possibilidades e limites na Constituição de 1988. 2004. 212 f. Dissertação (Mestrado em Direito) - Pontifícia Universidade Católica de São Paulo, 2004.

\section{COMO CITAR ESSE DOCUMENTO}

MÜLLER, Caroline Bitencurt; RECK, Janriê Robrigues. Controle da transparência na contratação pública no Brasil - o acesso à informação como forma de viabilizar o controle social da Administração Pública. Revista do Direito, Santa Cruz do Sul, v. 2, n. 49, p. 96-115, maio 2016. ISSN 1982-9957. Disponível em: <https://online.unisc.br/seer/index.php/direito/article/view/6897>. Acesso em: doi:http://dx.doi.org/10.17058/rdunisc.v1i48.6897. 